\title{
Schemata in Creative Thinking to Solve Mathematical Problems About Geometry
}

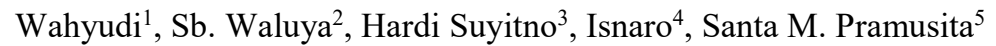 \\ \{yudhi@staff.uksw.edu ${ }^{1}$, s.b.waluya@mail.unnes.ac.id ${ }^{2}$, hardi.suyitno@mail.unnes.ac.id ${ }^{3}$ \} \\ Universitas Kristen Satya Wacana, Indonesia ${ }^{1}$, Universitas Negeri Semarang, Indonesia ${ }^{2,3}$
}

\begin{abstract}
The purpose of this study is to describe schemata and students creativiy in solving mathematical problem about Gemoetry. This study is qualitative reseach. The data of this research collected by the method of think out loud and task analysis, by giving test questions and conducting interview according to students responses. Miles and Huberman's analysis technique are used to analyzed the data. The result showed that there are varity of student" schemata based on their creativy in solving mathematical problems. Students with high creative thinking skills had complete and systematic schemata structures, while students with a creative enough category has incomplete schemata. The process of students with high creative thinking skills was arranged in coherent and systematic ways and diverse answers. The incomplete schemata made them not be able to find the relationship between concepts. Students with less creative category has an unfavorable schemata, cannot provide a solution to the problem.
\end{abstract}

Keywords: schemata, creative thinking, solve mathematical problems, geometry

\section{Introduction}

The purposes of learning mathematics is to improve creative thinking skills in solving problems [1]. Creative thinking skills allow learners to create variety of solutions in amount and way used. Several factors are influenced creative thinking, and one of them are concept sheme built based on the students' experience or we can call it the prerequisite capabilities or background knowledge previosly owned [2]. These schemes will build a system called schemata [3].

Schemata is a collection of concept shemes representing a generic concept stored in memory, or it is also a plural form [4]. Schemata is a mental representation of some aspects that serve to compare someone's knowlege with new information, and goes into their memory [5]. Schemata develops based on one's experience [2] [4-6]. Schemata is what helps someone process new information until it solves the problem given to him. Schemata has important position of students' knowledge at the time of study, so teacher's role is really important to notice how the schemata is formed and stored in the students' memory. Teachers tend to focus to complete the material and prioritize things related to cognitive ability, therefor the main problem in learning is not all teaching understand it. Mathematics learning has not provided the opportunity for students to improve reasoning and thinking skills in solving problems [10,11]. Math learning is becoming a lesson that students don't. This leads to the student's creativity in solving the problem of being low. 
Creative thinking can be as the ability to process information, which is the part of a person's biological development and knowledge, including Metacognition [7]. A person will use his or her metacognitive skill when he or she is able to organize and compile information using his or her experience. Schemata is really close to the improvement of creative thinking and has an important role in the development of one's thinking logic which is the logic of thinking will help someone in solving the problem, encountered including in solving problem of mathematic [8].

Thus it takes the right way how to see how schemata is formed and how the schemata arrangement is stored in one's memory. This research will give an overview of how a person's schemata is constructed and develops from his creative thinking ability. This research will focus on three types of schemata i.e. formal schemata, content and linguistics for geometric material builds flat.

\section{Method}

\subsection{Design of the Study}

This research was a qualitative research. The research design uses qualitative triangulation where the validity of data ability of creative thinking, thinking schemata seen from the result of test and interview. The scope of this research included the descriptions of the ability of mathematical creative thinking and thinking schemata.

\subsection{Participant}

This qualitative research has 30 participants they are students of pre-service primary school teacher. The technique used is a non-probability sampling technique to select the participant, which is each member of population, does not have the same opportunity to be the subject research. The type of non-probability sampling used is purposive sampling, which is the taking of subject used if the research has certain considerations with certain objectives.

\subsection{Technique and Data Collection Instrument}

The method of think out loud [12] and task analysis [13] are used to collect the data in the form of creative thinking processes and thinking schemata, by giving test questions and conducting interview according to students responses and viewed from the components of thinking system. Cognitive activity that occurs in a person's mental or mind, is not visible, but can be inferred from visible behaviour is called thinking [14-16]. The type of schemata in this reseach used opinion by Shuying An [1] and Dixon and Zhao [17] which has been modified based on the reseach needs, namely about mathematics, creative thinking, and geometry material of plane.

\subsection{Data Analysis Technique}

The data analysis conducted through qualitative which includes several steps of data reduction, display and drawing conclusion [18-20]. 


\section{Results \& Discussion}

\subsection{Mathematical Creative Thinking Initial Level}

Creative thinking skills are measured by tests that have been faltered by 5 experts in the field of mathematics. The mean of test results are 60.47 with the standard deviation of 9.10 with the standard of precast error 1.66. of the participants have creative thinking skills with medium and low categories of $93.33 \%$ (28 participants).

\subsection{Schemata in Creative Thinking}

The schemata in creative thinking can be seen from student answers and interviews based on these answers which include formal schemata, content schemata, linguistic schemata. To give a description of creative thinking schemes then selected 3 subjects with the ability to think creatively in the creative category, quite creative, and less creative. Here are the questions given to the 3 selected subjects.

\subsection{A park was designed as the picture below.}

The park is 11 meters long and 8 meters wide. At the two ends of the park there are each fish pond with a radius of 3.5 meters which EF is 2 meters.

I= Fish Pond ; II= Grass; $\boldsymbol{I I I}=$ Pathway

Determine all possible ways to determine the area of land planted with grass!

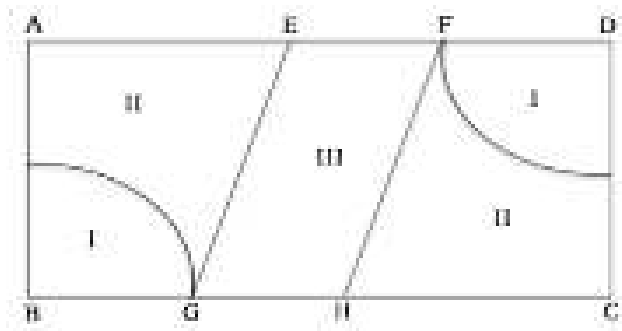

Figure 1. Picture of Equation 1

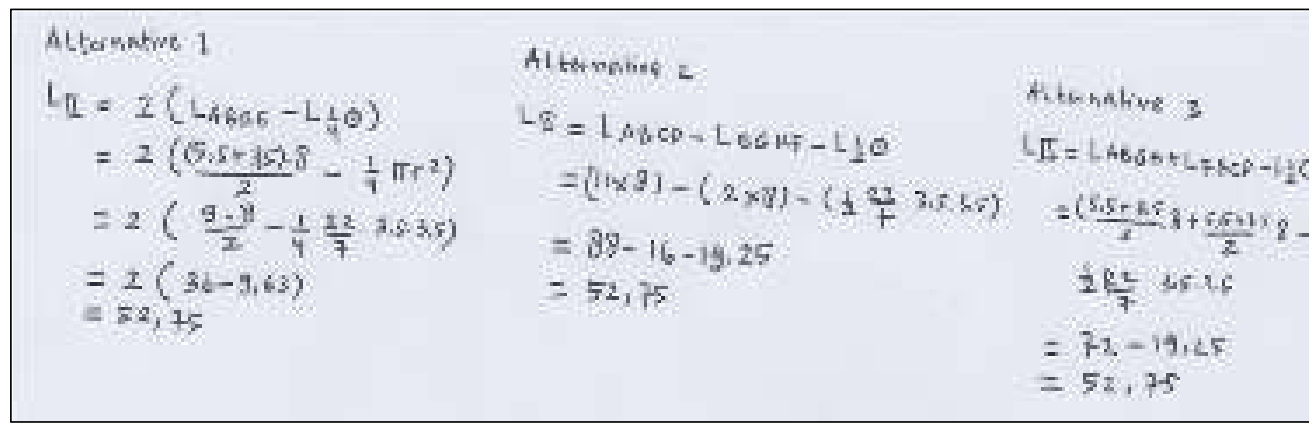

Figure 2. Example of answers to subjects with creative categories 
As per the answer to the subject 1 (creative), the next step taken was an interview. The interview results for subject 1 (creative) can be seen from the recap of the following interview. In accordance with the answers in the interview, then the subject 1 can be identified when thinking creatively according to the answer.

Table 1. Type and descriptions of the schematic in thinking subject 1 (creative)

\begin{tabular}{ll}
\hline $\begin{array}{l}\text { Type of } \\
\text { Schemata }\end{array}$ & Note \\
\hline Formal Schemata & $\begin{array}{l}\text { Subject } 1 \text { had very good initial knowledge as a prerequisite concept. } \\
\text { The concepts included angle, side, base, height, parallel, right angle, } \\
\text { area, and circumference, even the concept of parallelogram, circle, } \\
\text { trapezoid, and rectangle. This was what facilitated subject } 1 \text { to produce } \\
\text { several alternative answers in a variety of ways by determining the } \\
\text { relationship between the concepts. }\end{array}$ \\
The theme content of subject 1 was also very good. The subject \\
Tontent & $\begin{array}{l}\text { understood in detail what parallelogram, circle, trapezoid, and } \\
\text { rectangle was as the main problem to solve. The subject was able to } \\
\text { explain the definition and characteristics of parallelogram, circle, } \\
\text { trapezoid, and rectangle thus it makes it easier for the subject to solve } \\
\text { the problem. The relationship between concepts as a prerequisite can } \\
\text { also be associated with the parallelogram, circle, trapezoid, and } \\
\text { rectangle concept well, making it easier to solve problems. } \\
\text { Subject } 1 \text { linguistic schemata was also very good. Many terms can be } \\
\text { conveyed by the subject such as angle, side, base, height, parallel, right } \\
\text { angle, width, circumference, perpendicular up to straight, parallel, } \\
\text { diagonal side, even the subject had a special term to make it easier to } \\
\text { remember the parallelogram, circle, trapezoid, and rectangle concept. } \\
\text { This was done so that there wouldn't be too many things to be stored in } \\
\text { the brain. }\end{array}$ \\
\hline
\end{tabular}

These results indicate that subjects with creative categories have excellent and complete schemata in both formal, content and linguistic schemata. This is what makes the assimilation process work well. The good process of adaptation is what allows the formation of interrelated concept schemes that are schemata in the memory of students [4]. This schemata will be the capital of the student can solve the problem given to him. This will make the adaptation process run well so that knowledge will continue to build up according to the good experience received by each student [2]. It is in line with the opinions, that a person's schematic will grow in line with his experience [2] [4-6] [21]. Existing concepts are well organized and can be used to solve problems. Based on these results it can be concluded that the subject has a good and complete scheme, the ability to think creatively is also good (creative). It is in accordance with the study of Corcoran [8], where schemata is very close to the improvement of creative thinking and has an important role in the development of one's thinking logic. The logic of thinking is what will help someone in solving the problems encountered including in solving mathematical problems [8]. 


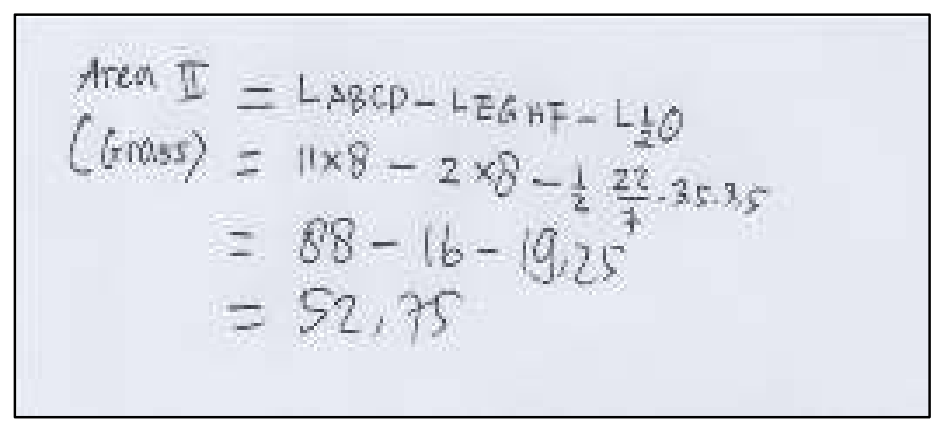

Figure 3. Example of answers to subjects with creative enough category

As per the answer to the subject 2 (quite creative) there are 1 correct answers. In accordance with the answers in the interview, then the subject 2 can be identified when thinking creatively according to the answer to question number 1.

Table 2. Type and descriptions of the schematic in thinking subject 2 (quite creative)

\begin{tabular}{|c|c|}
\hline $\begin{array}{l}\text { Formal } \\
\text { Schemata }\end{array}$ & $\begin{array}{l}\text { Subject } 2 \text { had initial knowledge not yet complete as a prerequisite } \\
\text { concept. The concepts possessed include area, base, height, } \\
\text { parallelogram, circle, and rectangle. This concept helped subject } 2 \text { to } \\
\text { produce several alternative answers. }\end{array}$ \\
\hline Con & The theme of subject 2 content about parallelogram, circle, and rectangle \\
\hline Sche & $\begin{array}{l}\text { was only limited as a stand-alone rectangular building. Subject } 2 \text { only } \\
\text { memorized the wide parallelogram, circle, and rectangle. The } \\
\text { relationship between concepts as a prerequisite was only related to } \\
\text { parallelogram, circle, and rectangle. }\end{array}$ \\
\hline $\begin{array}{l}\text { Linguistic } \\
\text { Schemata }\end{array}$ & $\begin{array}{l}\text { Subject } 2 \text { linguistic schemata was limited to area, base, height, } \\
\text { parallelogram, circle, and rectangle. This also limited Subject } 2 \text { to } \\
\text { produce other problem solving alternatives. }\end{array}$ \\
\hline
\end{tabular}

These results indicate that subject 2 with a quite creative category has an incomplete schemata, only focusing on 2 concepts namely parallelogram, circle, and rectangle. Nevertheless the assimilation process went well, especially those related to parallelogram, circle, and rectangle thus it was able to provide one solutions to the problem. Subject 2 has not seen other concepts such as trapezoid, this causes subject 2 to only produce 1 solutions. What is interesting from the results of interviews is that learning patterns of plane was done partially, not paying attention to the relationship between plane building, so when asked about the relationship and classification the subject experiences confusion and cannot describe the relationship. These results indicate that the schemata that the subject has affects the ability of creative thinking in generating solution problems. It is in accordance with the study of Corcoran [8], where schemata is very close to the improvement of creative thinking. 


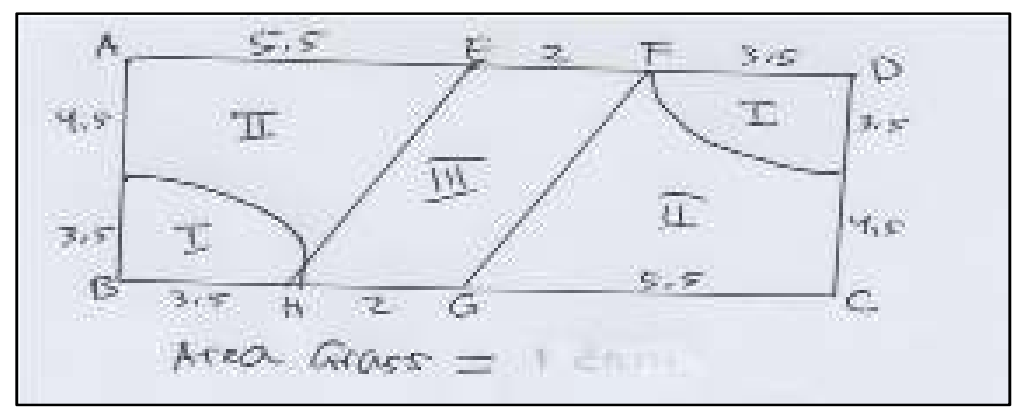

Figure 4. Example of answers to subject with less creative category

As per the answer to the subject 3 (less creative) there was no right answer. In accordance with the answers in the interview, then the subject 1 can be identified when thinking creatively according to the answer to question number 1.

Table 3. Type and descriptions of the schematic in thinking subject 3 (less creative)

\begin{tabular}{ll}
\hline Formal & Subject 3 did not have good initial knowledge as a prerequisite concept. Only \\
Schemata & rectangular concepts in general, and forgot the concepts that existed in the \\
problem given. The subject also experienced confusion in building a & rectangle that was the problem. \\
Content & The content schemata of subject 3 on parallelogram, circle, trapezoid, and \\
Schemata & rectangle was very weak, even having difficulty identifying that the \\
problems presented are related to parallelogram, circle, trapezoid, and & \\
Linguistic & rectangle. \\
Schemata & The subject's linguistic schemes were only limited to rectangular flat, \\
& rectangular, wide, but many forgotten names.
\end{tabular}

These results indicate that subject 3 in the less creative category has an unfavorable schemata. This caused subject 3 cannot provide a solution to the problem. The assimilation process did not go well, many forgotten concepts even some were unknown to them. What's interesting about the results of the interview is that subject 3 did not like learning mathematics. Subject 3 did not feel comfortable and happy while studying mathematics, even tended to be afraid. This is what caused not many mathematical concepts stored in the subject's memory 3 .

It is not in line with the current mathematical learning paradigm, where mathematics is close to humans, mathematics is part of human culture [22-24] and is part of social reality $[22,25]$. Learning must be made to a real, challenging and engaging problem so that students are interested in learning. This fun situation will make the mathematical concept can be remembered as a beautiful memory in the students ' memories so that the formal schemata and content schemata will be well formed.

\section{Conclusion}

The results showed that students' schemata varied according to their creativity in solving mathematical problems. Students with high creative thinking skills had complete and systematic 
schemata (formal, content, and linguistic) structures. The process of problem solving was arranged in coherent and systematic ways with diverse answers. New schemata were well formed and produced balanced new knowledge. Students with a creative enough category has an incomplete schemata. Their formal schemata is incomplete so as to not be able to find relationships between concepts. Students with less creative category has an unfavorable schemata. They cannot provide a solution to the problem. They did not like learning mathematics. They did not feel comfortable and happy while studying mathematics, even tended to be afraid. 


\section{References}

[1] Nadjafikhah, M., Yaftian, N., \& Bakhshalizadeh, S. (2012). Mathematical creativity: some definitions and characteristics. Procedia-Social and Behavioral Sciences, 31, 285-291.

[2] Piaget, J. (1980). The psychogenesis of knowledge and its epistemological significance.

[3] An, S. (2013). Schema Theory in Reading. Theory and Practice in Language Studies, 3(1), 130134.

[4] Rumelhart, D. E., Norman, D. A., Aitkenbcad, A. M., \& Slack, J. M. (1985). Issues in cognitive modeling. 'Representation of Knowledge'.

[5] Cook \& Guy. 1989. Discourse. Oxford: Oxford University Press.

[6] Neumann, K. L., \& Kopcha, T. J. (2018). The Use of Schema Theory in Learning, Design, and Technology. TechTrends, 62(5), 429-431.

[7] Flavell, J. H. 2004. Theory-of-Mind Development: Retrospect and Prospect. Merrill-Palmer Quarterly, 50(3), 274-290. https://doi.org/10.1353/mpq.2004.0018

[8] Corcoran, J. (2006). Schemata: the concept of schema in the history of logic. Bulletin of Symbolic Logic, 12(2), 219-240.

[9] Wahyudi, Waluya, S. B., Rochmad, \& Suyitno, H. (2018). Assimilation and Accommodation Processes in Improving Mathematical Creative Thinking with Scaffolding According to Learning Style. In Journal of Physics: Conference Series(Vol. 1097). Institute of Physics Publishing. https://doi.org/10.1088/1742-6596/1097/1/012156

[10] Cracolice, M. S., Deming, J. C., \& Ehlert, B. (2008). Concept learning versus problem solving: a cognitive difference. Journal of Chemical Education, 85(6), 873.

[11] Vyas, D., Ottis, E. J., \& Caligiuri, F. J. (2011). Teaching clinical reasoning and problem-solving skills using human patient simulation. American journal of pharmaceutical education, 75(9), 189.

[12] Charters, E. (2003). The use of think-aloud methods in qualitative research an introduction to think-aloud methods. Brock Education: A Journal of Educational Research and Practice, 12(2).

[13] Someren, M. W., Barnard, Y. F., \& Sandberg, J. A. C. (1994). The think aloud method: a practical approach to modelling cognitive. Academic Press, London.

[14] Mayer, R. E. (2002). Rote versus meaningful learning. Theory into practice, 41(4), 226-232.

[15] Mayer, R. E. (2013). Incorporating motivation into multimedia learning. Learning and Instruction, 29, 171-173.

[16] MacLin, M. K., \& Solso, R. L. (2008). Experimental psychology: a case approach. Pearson/Allyn \& Bacon.

[17] Dixon, L. Q., Zhao, J., Shin, J.-Y., Wu, S., Su, J.-H., Burgess-Brigham, R., ... Snow, C. (2012). What We Know About Second Language Acquisition: A Synthesis From Four Perspectives. Review of Educational Research, 82(1), 5-60. https://doi.org/10.3102/0034654311433587

[18] Miles, M. B., Huberman, A. M., Huberman, M. A., \& Huberman, M. (1994). Qualitative data analysis: An expanded sourcebook. sage.

[19] Creswell, J. W. (2012). Educational research: planning. Conducting, and Evaluating.

[20] Bazeley, P., \& Jackson, K. (Eds.). (2013). Qualitative data analysis with NVivo. Sage Publications Limited.

[21] Longo, G., \& Perret, N. (2018). Rhythms, Retention and Protention: Philosophical Reflections on Geometrical Schemata for Biological Time. In Building Theories (pp. 245-259). Springer, Cham.

[22] Hersh, Reuben. 1997. What is Mathematics, Really?. London: Jonathan Cape.A Dyer, J., Gregersen, H., \& Christensen, C. M. (2011). The innovator's DNA: Mastering the five skills of disruptive innovators. Harvard Business Press.

[23] Greer, B. (1997). Modelling reality in mathematics classrooms: The case of word problems. Learning and instruction, 7(4), 293-307.

[24] Rosa, M., \& Orey, D. (2011). Ethnomathematics: the cultural aspects of mathematics. Revista Latinoamericana de Etnomatemática: Perspectivas Socioculturales de La Educación Matemática, 4(2), 32-54.

[25] Zevenbergen, R., Dole, S., \& Wright, R. J. 2004. Teaching mathematics in primary schools. 
Crows Nest: Allen \& Unwin.

[26] Gardner, H. 1993. Creating minds. New York: Basic Books. 